\title{
Revisiting the genus Aethaloptera Brauer (Trichoptera, Hydro- psychidae, Macronematinae): new species and records
}

\author{
J. OLÁH
}

\author{
János Oláh, Residence postal address: Tarján u. 28, H-4032 Debrecen, Hungary.E-mail: profolah@gmail.com
}

\begin{abstract}
The taxonomic potential of speciation traits, the adaptive structural components of the phallic head that build the early stages of reproductive barriers was applied in our first revision of the Aethaloptera genus with unsettled obscured taxonomy. The present paper complements the first revision and is based on the examination of the historical Aethaloptera collection of the Natural History Museum, London. The difficulty of presenting the tiny, subtle, but stable divergences in the speciation traits is discussed. The presented graphical copy of phenomic reality delineates species reliably if the matrices of the drawings from various populations, clearly visualizes empirically, without geometric morphometrics, that the detected shape divergences are larger than the combined variation ranges of the artefacts and of the infra-populations. Based upon the lateral profiles of the phallic head two new species complexes: A. dispar and A. maxima and four new species have been described: A. nulta sp. nov., A. pipa sp. nov., A. feltora sp. nov. and A. pricei sp. nov.
\end{abstract}

Keywords. Speciation trait, phallic head, new species.

\section{INTRODUCTION}

$\mathrm{T}$ he taxonomy of Aethaloptera genus was based primarily on tibial spur formula, on wing venation and on forewing pattern of the brown spots (Kimmins 1962). Most of these characters are represented by neutral traits less stabilised in the elaborated networks of protective mechanisms against the stochastic nature of random impacts. Already Kimmins (1962) has recognised that male genitalia, though similar, are not uniform in details and the variations do not correlate with spur and wing characters. This discordance has generated the widespread view of the widely distributed and highly variable species. Accordingly the four African species were considered to represent only a single species with local forms (Kimmins 1962). Others have suggested a more diverse nature of the genus, at least in the Afrotropical faunal region (Lestage 1936, Marlier 1943, Statzner \& Gibon 1984, Ogbogu 2005). Only a detailed study of long series of specimens could help to solve the taxonomy of the Aethaloptera genus (Barnard 1980). However, the principle and practice of population sampling that is to collect large number of specimens from each habitat is only a dream in the present devastated state of our taxonomy.

The discovery of speciation traits, the adaptive structural components of the phallic organ that build the early stages of reproductive barriers, has initiated our first trial to revise the obscured Aethaloptera genus applying the lateral profile of phallic head for species delineation (Oláh 2018). After publishing this paper we have received the entire Aethaloptera collection of the Natural History Museum, London to supplement our first trial. In this paper we give some additional evidences of subtle, but stable divergences between the phallic head of species. We demonstrate the stability and applicability of the phallic head, as adaptive speciation trait in new species delimitation based on the re-examination of some old historical specimens kept pinned and dry as well as on the study of materials from some new collections stored in alcohol. The immense taxonomic potential of the complex invaginated internal structures is not utilised here in distinguishing between species. 


\section{How to present subtle divergences?}

At the Macronematinae subfamily the highly specialised derived state in the organisation of the phallic structure is the result of modification by reduction and simplification, a kind of complexity increase by incremental subtraction (Esteve-Altava et al. 2013). The primordial phallic structures (aedeagus, endotheca, endophallus, and endothecal processes) have been abbreviated and moved to the apical region of the phallotheca. Thereafter they became retracted (inverted or invaginated) inside the very tip of the tubular phallotheca (Oláh 2018). The resulted compact phallic head retained or even increased its complexity by inversion, anisomerism, unpaired structures, density of connections, path and cluster development (Oláh et al. 2014). The simple head with this inverted complexity is under the permanent pressure of sexual integration. This intense pressure has induced and powered the apparently high diversity of adaptive shape divergences.

The neutral traits of spur number, wing venation and forewing spot pattern are exposed to stochastic mechanisms with random variation. The adaptive speciation trait of the phallic head with very elaborated and complex internal structure has subtle, but well-defined and rather stable shape divergences. Its stability is maintained by a network of very complex protective mechanisms (Oláh \& Oláh 2017). Moreover, we have learnt from sophisticated molecular genetic studies on Drosophila genus that even a very simple divergence in shape profiles, like a simple lobe on a key genitalic structure, is organised, produced and protected by very complex cooperation of several thousand sequences in quantitative trait loci and superimposed by epistatic and epigenetic interferences and sequence interactions (Oláh et al. 2017). It was just a modern wishful dream of reductionism in the gene industry to abstract the reality into mathematical and statistical models how the building of such a complex system like the inverted phallic head of the Aethaloptera genus with incremental subtraction is organised by integration on molecular level.
Studying subtle phenomic differences on the speciation traits we work nearby the structural diverging point of the initial split criteria. Contrary to the basic problem of genomic virtuality, here we face the challenge how to present, by drawings, the phenomic reality of speciation trait with tiny shape divergences in fine phenomics, because: (1) according to the "identity of indiscernibles" every entity is different; (2) therefore every subtle and stable divergence of speciation trait has some level of individual variation; (3) moreover, there are various hybrids from contact zone with intermediate byproducts; (4) every consecutive drawings prepared by the same person from the same individual is different; (5) every person has different drawing style and capacity. In addition to these challenges we have surveyed eleven potential sources of artefacts in order to pay due attention in distinguishing between subtle adaptive divergences, artefacts and infra-population trait variations (Oláh et al. 2015).

The best empirical solution to the presentation problem of these tiny divergences is to compose and to build matrices of the drawn diverged speciation traits from as much populations as possible. We use the world "matrix" in its original sense: the basic material of something, the ground, the origin or the parent Mather (=mater) of species delineation. This original sense of "everything" is abstracted in mathematics to rectangular array of grids, in rows and columns to express numbers, symbols or anything when using the world "matrix". This graphical copy of phenomic reality delineates species reliably if the matrices of the drawings from various populations, clearly visualizes empirically, without geometric morphometrics, that shape divergence is larger than the combined variation range of artefacts and of infra-populations. We have experienced and documented in several caddisfly taxa that the epistemic power/visual perception of the multiple drawings concentrated in matrices is demonstrative and convincing compared to the single drawing of a particular specimen (Oláh et al. 2013, 2014, 2015, 2016, 2017).

In Aethaloptera genus the drawings of lateral profile of the phallic head properly observable by 
stereomicroscopy are the most stable form of presentation to document species level divergences. The dorsal, ventral and caudal forms of phallic head are not stable; their actual shape is highly dependent on the opening state of the aperture rim, moreover the caudal view is very sensitive to slight changes of viewing angles.

\section{MATERIALS AND METHODS}

The old historical material of MacLachlan, Ulmer, Martynov, Mosely and Kimmins deposited in the Natural History Museum, London are composed of mostly pinned female specimens. The study of old dry pinned specimens is not easy and is highly taxon-specific. We need to cut some apical abdominal segments with the genitalia or need to remove the entire abdomen for cleaning, clearing and dissecting. Frequently we need to cut the head and thorax also for preparation. In some taxa like Rhyacophila the abdomen removal from pinned dry specimens is easier. In the case of Aethaloptera female it is almost impossible. The abdomen is usually fully packed with eggs and usually broken together with the metathorax. Moreover female taxonomy, especially at the Afrotropical species is not elaborated. We believe that in the case of caddisflies it is advisable to transfer dry pinned ordinary specimens to alcohol; otherwise its proper study is difficult or almost impossible, especially in the case of microcaddisflies. From the Natural History Museum, London we have examined all the materials which were stored in alcohol, but only those pinned specimens which have and give important taxonomical information at the present level of our knowledge.

Depositories. Natural History Museum, London, (NHMUK); formerly the British Museum Natural History, London, England (BMNH).

Oláh Private Collection, Debrecen, Hungary, under national protection by the Hungarian Natural History Museum, Budapest, Hungary (OPC).

Queensland Museum, Brisbane, Australia (QM).

Zoologisches Museum, Hamburg, Germany (ZMH)

\section{TAXONOMY}

\section{Aethaloptera Brauer, 1875}

Character ranking to establish the taxonomical position of the genus Aethaloptera has recently been summarized and presented by ranking synapomorphies (Oláh 2018). The Macronematinae subfamily was delimited in the Hydropsychidae family by the elongated antennae; the Polymorphanisini tribe by the vestigial mouthparts; the Aethaloptera genus by the false discal cell, the species group inside the Aethaloptera genus by the position of the aperture slit on the apical ending of the phallotheca; and the species by the shape of the phallic head.

\section{Aethaloptera dispar species group}

According to the area principle this is the ancestral species group being distributed in very large area over the Afrotropical, Palaearctic, Oriental and Australasian faunal regions. The area principle is confirmed by the fact that all members of the group have the plesiomorphic character state of the terminal opening of the phallotheca: the group is delimited by the apical or nearly apical, slightly apicodorsal position of the aperture rim of the invaginated distal end of the phallotheca, the entrance atrium and its apical opening with the rim configuration (Oláh 2018).

\section{Afrotropical species}

Based on discordances between variations of spur, wing and phallic head, Kimmins (1962) has considered that $A$. dispar and A. maxima may be only local forms of one widely distributed species. According to Lestage (1936) and Marlier (1943) $A$. dispar alone may represent 3 species just in Belgian Congo. Applying the adaptive speciation trait of the phallic head we distinguish two species complexes in the Afrotropical species of the $A$. dispar species group: (1) $A$. dispar species complex having phallic head somewhat rounded subqudrangular; (2) A. maxima species complex having phallic head simply rounded. 


\section{Aethaloptera dispar complex}

This is a well-defined species complex with rounded sub-quadrangular lateral profile of the phallic head. Further divergences in the complex are organised by the particular formation of subquadrangularity of the phallic head as well as by the neck and head formation.

\section{Aethaloptera dispar Brauer, 1875}

(Figures 1-7)

\section{Material examined. Democratic Republic of} the Congo (Congo, Zaire), 1900, leg. G.L.E. Andreae, 1900-38, NHMUK012501687, det. M. E. Mosely as $A$. dispar, (1 male, NHMUK).

Remarks. The obliquely upward directed phallic head is typically sub-quadrangular. The head is low, that is the neck is almost as high as the head. The genuine species of $A$. dispar is reported here from Senegal (Lectotype) through Ghana and Republic of Congo to Democratic Republic of Congo.

\section{Aethaloptera nulta sp. nov.}

(Figures 8-11)

Material examined. Holotype: Malawi. (Nyasaland), Ntundu, 7.VIII.1952, leg. Lewis Berner, 7-852-1, B.M.1953-668, NHMUK012501661, D. E. Kimmins det. 1954 as A. dispar (1 male, NHMUK). Paratypes: same as holotype (3 males, NHMUK; 1 male, OPC). Zambia, (North Rhodesia), Karambora, 1962, leg. E. Pinhey, B.M. 1962-428, NHMUK012501703, det. P.C. Barnard 1977 as $A$. dispar (2 males, 2 females; NHMUK). Zambia, (North Rhodesia), Karambora, Zambezi River, IV.1962, leg. E. Pinhey, B.M. 1962-428, NHMUK012501703, det. D.E. Kimmins 1962 as A. dispar (6 males, NHMUK; 3 males, OPC).

Diagnosis. The obliquely upward directed phallic head remained sub-quadrangular, but not typical of the nominate species $A$. dispar, somewhat widening apicad, somehow funnelling. The head is elongated, not low like in A. dispar that is the neck is only half as high as the head. The species is recorded from the basin of Zambezi River.
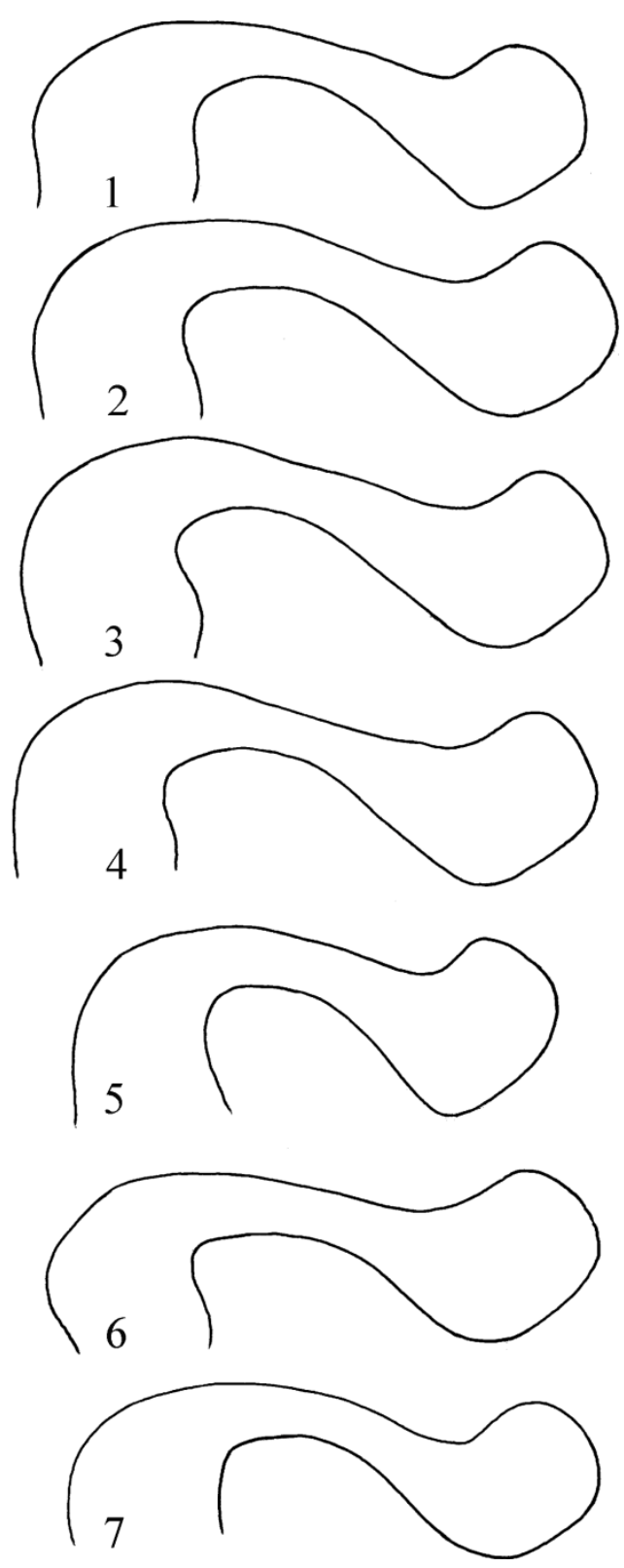

Figures 1-7. Aethaloptera dispar Brauer, 1875. Lateral profile of the phallic organ from various populations: $1=$ Lectotype from Senegal, drawn by Barnard (1980); $2-5=$ specimens from Republic of the Congo; 6 = specimen from Democratic Republic of Congo; 7 =specimen from Ghana drawn by Kimmins (1962).

Description. Medium-sized species. In alcohol the head and thorax yellowish brown, legs yellow, abdomen light, darker dorsally. Spur formula 032 . Forewing length around $10 \mathrm{~mm}$; wing colour pale, fading to yellowish brown; less pronounced and variously discernible seven brown spots present 
on cross-veins and on fork junctions. Sc and R1 sinuous apically, fork 4 is long stalked in forewing. Fork R4 in hindwing sessile. The basic structure of the male genitalia is similar to $A$. dispar, but differs by the divergences in the phallic head formation as discussed in diagnosis.

Etymology. nulta, from „nyult” lengthened, elongated in Hungarian, refers to the upward elongated head, twice the length of the phallic neck.
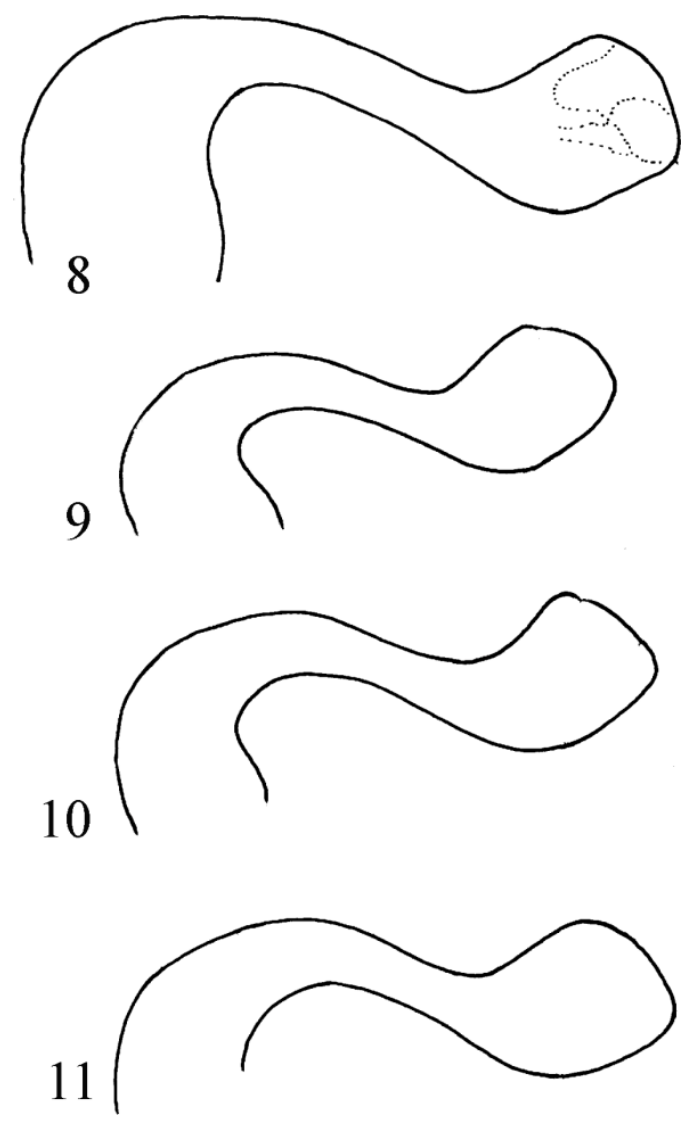

Figures 8-11. Aethaloptera nulta sp. nov. Lateral profile of the phallic organ from various populations: $8=$ Holotype male from Malawi; 9-11 = Paratypes from Zambia;

\section{Aethaloptera pipa sp. nov.}

(Figures 12-15)

Material examined. Holotype: Democratic Republic of the Congo (Belg. Congo), Kabalo, V.1926, leg. Dr. Schoubeden(?), 1935-232,
NHMUK012501658, det. M.E. Mosely as $A$. dispar (1 male, NHMUK). Paratypes: same as holotype (5 males, NHMUK; 1 male, OPC). Ghana, Black Volta, at light, 1967, leg. T. Petr, 1968-267, NHMUK012501700, det. D.G. Gibbs as $A$. dispar (1 male, NHMUK). Ghana (Gold Coast), Afram River, Mankrong,13.IX.1950, leg. Lewis Berner, Brit.Mus. 1953-668, NHMUK 012501654, det. D.E. Kimmins, 1957 and det. D. G. Gibbs as $A$. dispar (1 male, 1 female; NHMUK). Sierra Leone, Njala, II.-IV. 1925, at light, leg.E. Hargreaves, NHMUK012501640 (1 male, NHMUK).

Diagnosis. The obliquely upward directed phallic head remained sub-quadrangular, but not typical of the nominate species $A$. dispar, and not funnelling like $A$. nulta sp. nov. somewhat unregularly patterned, but pipe-shaped and usually concave apicoventrad and convex apicodorsad. The head is elongated, like $A$. nulta sp. nov. and not low like $A$. dispar; the neck is lower than the head. The specie is recorded from Sierra Leone to Democratic Republic of the Congo.

Description. Medium-sized species. In alcohol the head and thorax yellowish brown, legs yellow, abdomen light, darker dorsally. Spur formula 032. Forewing length around $12 \mathrm{~mm}$; wing colour pale, fading to yellowish brown; less pronounced and variously discernible seven brown spots present on cross-veins and on fork junctions. Sc and R1 sinuous apically, fork 4 is sessile in forewing. Fork R4 in hindwing sessile. The basic structure of the male genitalia is similar to A. dispar, but differs by the divergences in the phallic head formation as discussed in diagnosis.

Etymology. pipa, from ,pipa" pipe, tobacco pipe in Hungarian, refers to the pipe-shaped modification of the phallic head.

\section{Aethaloptera maxima complex}

This is a well-defined species complex with rounded lateral profile of the phallic head. Further divergences in the complex are organised by the particular formation of the circularity of the phallic head as well as by the neck and head formation. 

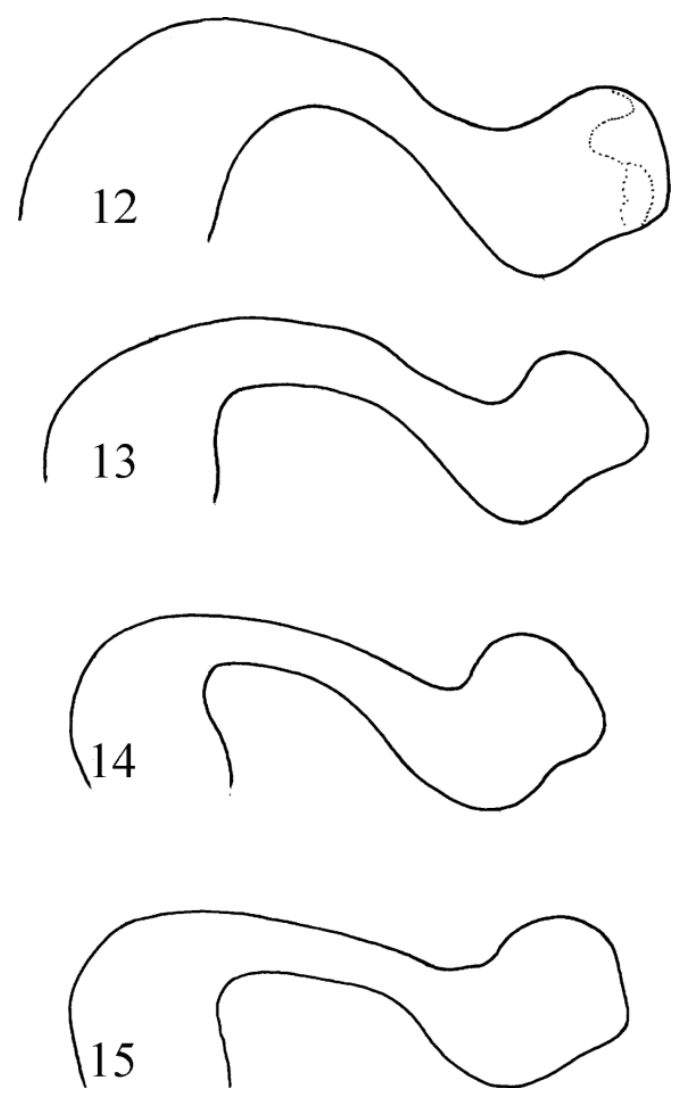

Figures 12-15. Aethaloptera pipa sp. nov. Lateral profile of the phallic organ from various populations: $12=$ Holotype male from Ghana, Volta River; 13 = Paratype from Ghana, Afram River; 14 = Paratype from Democratic Republic of the Congo; 15 = Paratype from Sierra Leone.

\section{Aethaloptera feltora sp. nov.}

(Figures 16-19)

Material examined. Holotype: Zambia, Chipepo, Middle Zambesi, 25.X.1956, ZGC145, caddis pupae and adults from tigerfish stomach (few free) (1 male, NHMUK). Paratypes: same as holotype (16 males, NHMUK; 6 males, OPC).

Diagnosis. The obliquely upward directed phallic head remained rounded, but not typical of the nominate species A. maxima, somehow particularly patterned. The dorsoapical region of the phallic head upward directed with a blunt tip; it has some resemblance to a water drop.
Description. Large-sized species. In alcohol the head and thorax yellowish brown, legs yellow, abdomen light, darker dorsally. Spur formula 022. Forewing length around $14 \mathrm{~mm}$; wing colour pale, fading to yellowish brown; less pronounced and variously discernible seven brown spots present on cross-veins and on fork junctions. Sc and R1 sinuous apically, fork 4 is stalked in forewing. Fork R4 in hindwing sessile. The basic structure of the male genitalia is similar to A. maxima, but differs by the divergences in the phallic head formation as discussed in diagnosis.

Etymology. feltora, from ,feltör" upwards in Hungarian, refers to the upward directed apicodorsal region of the phallic head.
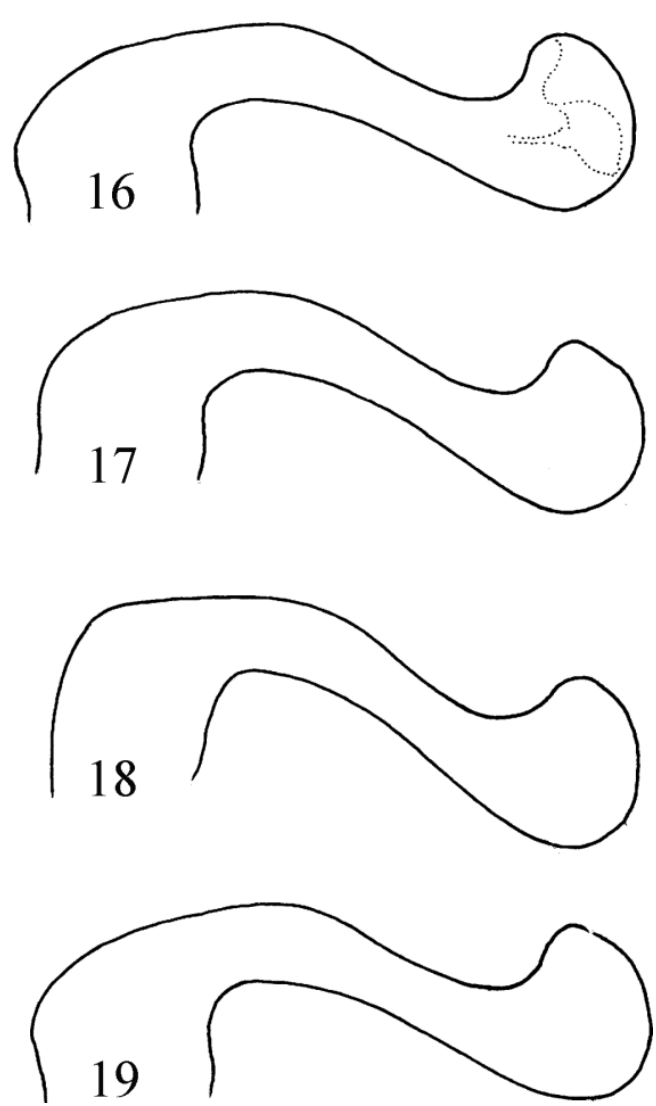

Figures 16-19. Aethaloptera feltora sp. nov. Lateral profile of the phallic organ: $16=$ Holotype male from Zambia, Middle Zambezi River; 17-19 = Paratypes from the Holotype's population. 


\section{Aethaloptera maxima Ulmer, 1906}

(Figures 20-25)

Material examined. Male holotype destroyed (Weidner 1964). Neotype examined, drawn, designated and deposited in the Zoologisches Museum, Hamburg by Barnard (1980). Here, two males were examined and drawn collected together with the neotype and deposited in NHMUK: South Africa, Waterval River, National Road between Standerton and Greylingstad, 12.I.1959, C.S.I.R. Water Research, VAL 518A, Brit. Mus. 1960-383, NHMUK012501652, D.E. Kimmins det. as A. maxima (2 males, BMNH). Zambia (North-East Rhodesia), Upper Luangwa R., 27.VII.-13.VIII.1910, leg. S.A. Neave, 1911177, NHMUK012501597, det. D.E. Kimmins, 1960 as Chloropsyche maxima, (1 male, BMNH).

Remarks. The obliquely upward directed phallic head is typically rounded, almost circular. The head is low, that is the neck is almost as high as the head. The genuine species of A. maxima is reported here from South Africa and Zambia.

\section{Palaeartic species}

A single species represents the genus in the Palaearctic fauna region with a distributional range covering Far East Russia and China. The lateral profile of the phallic head is rather stable in all the known populations.

\section{Aethaloptera evanescens (McLachlan, 1880)}

Material examined. China, Pai-se, Kwangsi, 29.III.1939, leg. Richardson, NHMUK012501559, det. M.E. Mosely as $A$. rossica, det. P.C. Barnard 1977 as A. evanescens (1 male, NHMUK).

Remarks. The single male specimen from China, Kwangsi deposited in the Natural History Museum, London has lateral profile of the phallic head identical with specimens examined from Far East Russia (Oláh 2018).
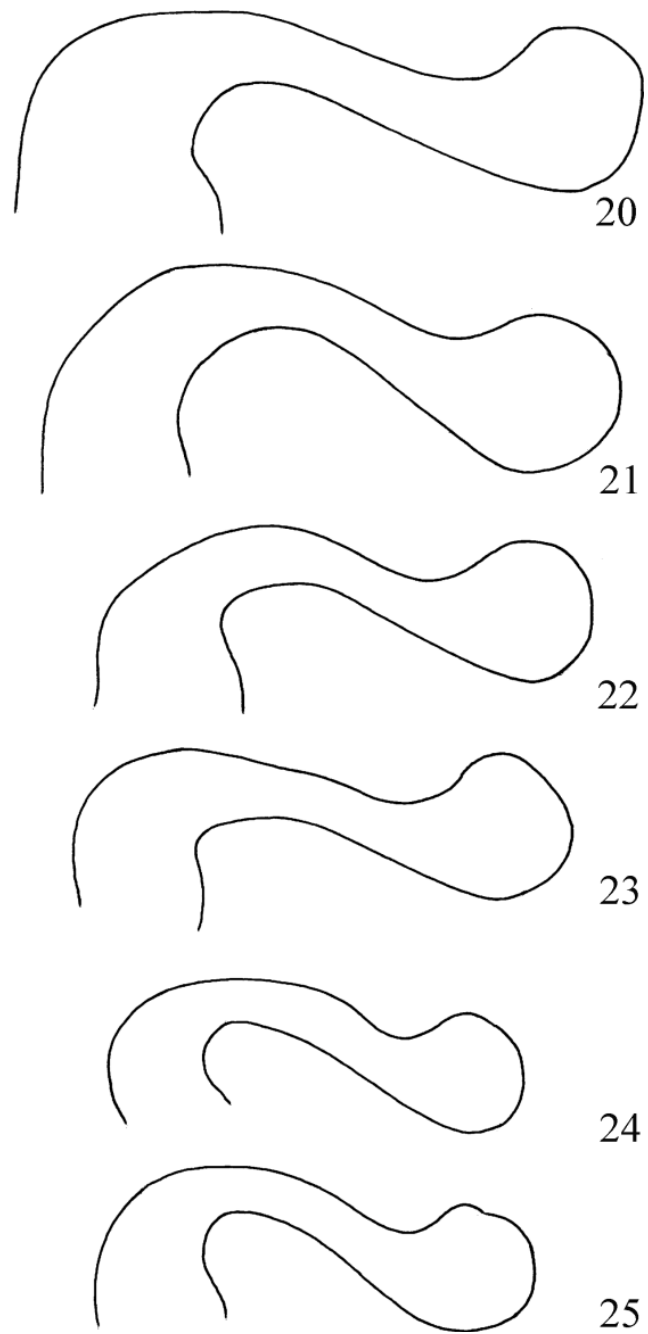

Figures 20-25. Aethaloptera maxima Brauer, 1906. Lateral profile of the phallic organ from various populations: $20=$ Neotype series from South Africa, Waterval River; $21=$ South Africa; Vaal River; 22 = Namibia, Orange River; $23=$ Namibia, Rundu; 24-25 = South Africa, Kunene River.

\section{Oriental species}

\section{Aethaloptera dyakana Banks, 1920}

(Figure 26)

Material examined. Brunei, 200', Rampayoh River, waterfall below LP 195, 1-3.III.1982, leg. G.S. Robinson, 7-852-1, BM.1982-156, NHMUK 

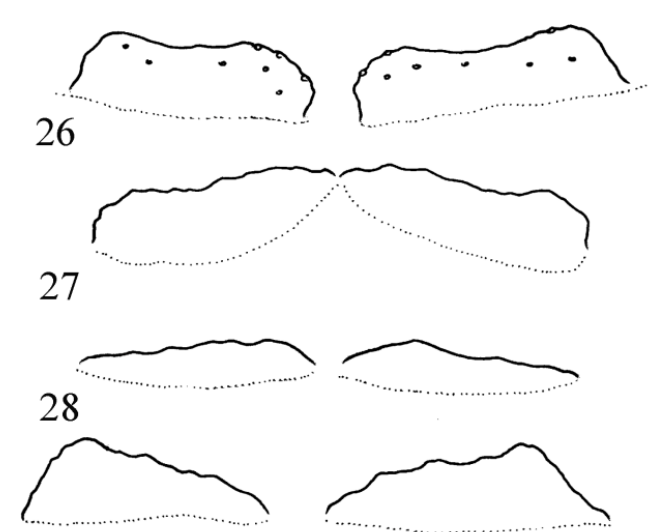

29
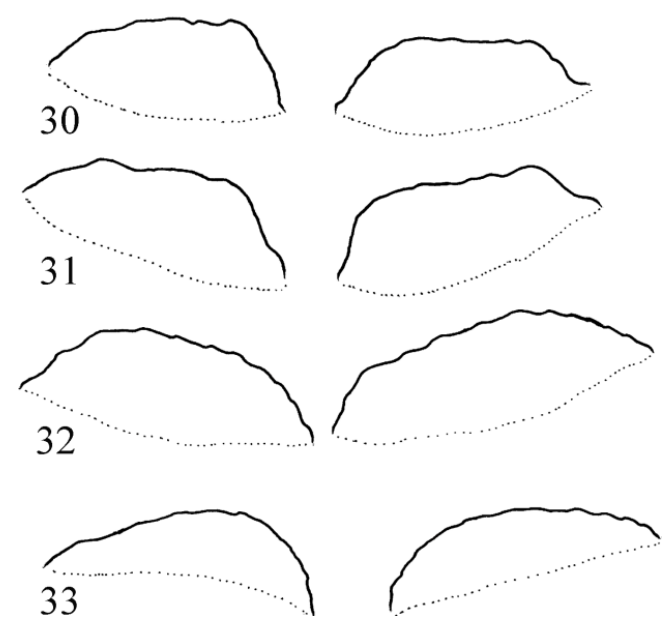

Figures 26-33. The pair of setose sclerites on sternite VIII of the known Oriental species: $26=A$. dyakana; $27=A$. malickyi $; 28=$ A. punctata $; 29=$ A. sexpunctata $; 30-32=$ A. wellsae from Australia; $33=$ A. wellsae from New Guinea.

012501678, det. P.C. Barnard 1982 as $A$. sexpunctata (1 female, NHMUK; 1 female, OPC).

Remarks. The species is known from a single female collected in Borneo. Ulmer (1951) has synonymized it with $A$. sexpunctata and Barnard (1980) also listed it under $A$. sexpunctata. Based on area principle it was reinstated as a valid species (Oláh 2018). Here we have examined the pair of setose sclerites on the sternite VIII of a female specimen from Brunei and it was clearly diverged and distinguishable from the setose sclerites of the known Oriental species. The setose sclerites are rather high compared to A. malickyi and $A$. punctata; sub-quadrangular with concave dorsum, not laterad triangular like $A$. sexpunctata or hump shaped like $A$. wellsae.

\section{Aethaloptera punctata (Banks, 1920)}

(Figure 28)

Material examined. Indonesia, Sumatra, Lahat, 1916, leg. John Henderson Esq., slide, NHMUK010114297, Mosely Coll. B.M. 1938443 (1 female, NHMUK). Malaysia, Perak, Ipoh, Kinta River, XI.1913-III.1914, leg. J. Henderson, NHMUK012501662, det. P.C. Barnard as A. sexpunctata (2 females, 1 female without genitalia, NHMUK). Malaysia, Brit. Mus. slide No 98, NHMUK010114298, det. P.C. Barnard as A. sexpunctata (1 female, NHMUK).

\section{Aethaloptera sexpunctata (Kolenati, 1859)}

(Figure 29)

Material examined. India, Bihar, Pusa, 27.II. 1924, leg. Krishna, T.B. Fletcher Coll. Brit. Mus. 1936-643, NHMUK012501526, det. M.E. Mosely as $A$. sexpunctata (1 male, NHMUK). Myanmar (Burma), Prome, 17.II.1917, at light, NHMUK 012501545 , det. M.E. Mosely as A. sexpunctata (1 male, NHMUK).

\section{Australasian species}

\section{Aethaloptera wellsae Oláh, 2018}

(Figures 30-33)

Aethaloptera wellsi Oláh, 2018: 11-13. The incorrect original spelling is corrected here as a justified emendation: Aethaloptera wellsae Oláh, 2018.The holotype was repatriated from MPC to QM.

Material examined. Australia, $20 \mathrm{mls} \mathrm{W}$ of Tully, Q. 20.IV.1964, leg. I. F. B. Common \& M. S. Upton, NHMUK012501540 (1 female, NHMUK). New Guinea, Port Moresby, 1887, leg. Kowald, McLachlan Coll. B. M. 1938-674, B. M. genitalia slide $\odot$ 99, NHMUK012501546 (1 female, NHMUK). Brit. Mus. Slide No. 99, NHMUK010114296, female genitalia, det. P.C. Barnard as A. sexpunctata.

Remarks. On the New Guinean specimen the wing venation and forewing spot pattern are simi- 
lar to A. wellsae Oláh, 2018 described from nearby in northeastern Australia. The pair of setose sclerites on the eighth sternite seems more regularly arch-shaped on New Guinean specimen. This is the first record of $A$. wellsae in New Guinea.

\section{Aethaloptera meyi species group}

This derived species group with restricted distribution to the Afrotropical fauna region was established by the anterad moved dorsal position of the aperture rim of the invaginated distal end of the phallotheca, the entrance atrium and its apical opening with the rim configuration.

\section{Aethaloptera meyi Oláh, 2018}

Material examined. Uganda, West Nile, A1bert Nile, Pakwach, 26,29.IV.1956, leg. P.S. Corbet, B.M.1956-751, det. as A. dispar (150 males, BMNH; 6 males, OPC). Uganda, West Nile, near Laropi, 27-28.IV.1956, leg. P.S.Corbet, B.M. 1956-751, NHMUK 012501701, P.S. Corbet E.A.F.R.O.Coll. det as $A$. dispar, (9 males, BMNH). Uganda, Victora Nile, L. Kyoga, near Namasale, 1.V.1956, leg. P.S. Corbet, 1956-751, P.S.Corbet E.A.F.R.O Coll. 157, det. as A. dispar (4 males, 10 females; BMNH). Sudan (South Sudan), White Nile, Sudd, Jonglei VIII, lagoon, $6^{\circ} 50^{\prime}-7^{\circ} 08^{\prime} \mathrm{N}, \quad 31^{\circ} 18^{\prime}-30^{\circ} 50^{\prime} \mathrm{E}$, January 1983 , leg. P. Warig, pres. Roland Bailey, NHMUK 012501655 , det. P.C. Barnard 1983 as A. dispar (1 male, OPC).

\section{Aethaloptera pricei sp. nov.}

(Figures 34-38)

Material examined. Holotype: Sudan (South Sudan), White Nile, Sudd, Jonglei VIII, lagoon, $6^{\circ} 50^{\prime}-7^{\circ} 08^{\prime} \mathrm{N}, 31^{\circ} 18^{\prime}-30^{\circ} 50^{\prime} \mathrm{E}$, January 1983 , leg. P. Warig, pres. Roland Bailey, NHMUK 012501655 , det. P.C. Barnard 1983 as A. dispar (1 male, BMNH). Paratypes: same as holotype ( 7 males, BMNH; 3 males, OPC).

Diagnosis. In the obscured taxonomical state of the genus this remarkable species distinguished
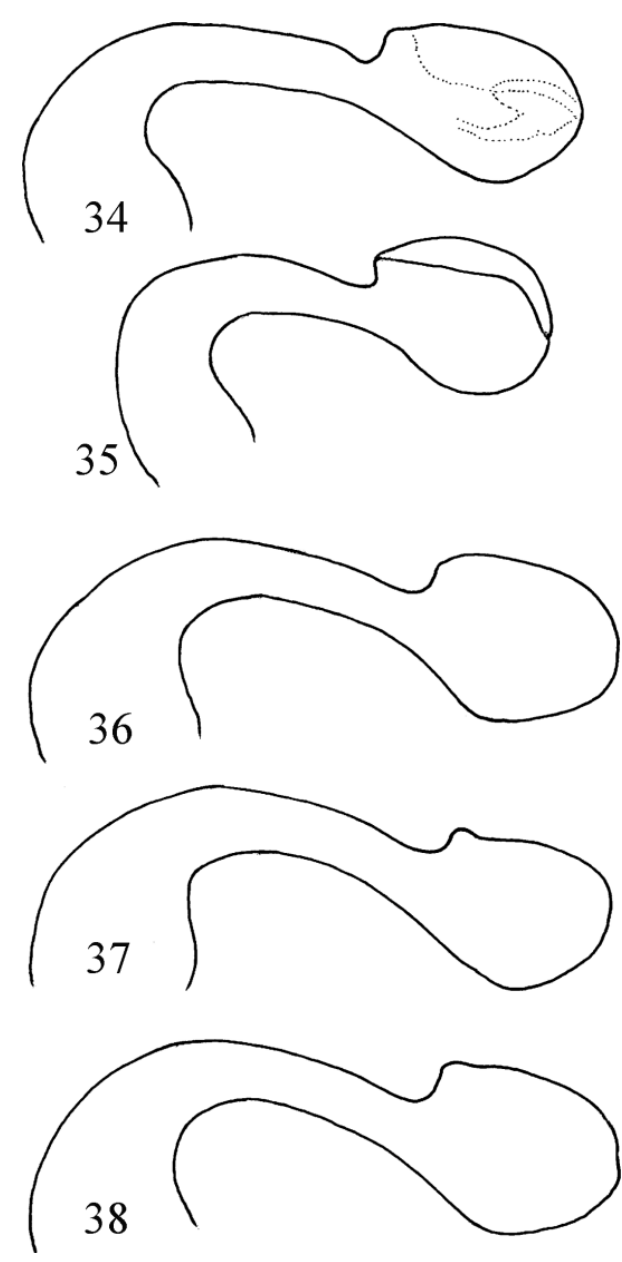

Figures 34-38. Aethaloptera pricei sp. nov. Lateral profile of the phallic organ from various populations: $34=$ Holotype:

Sudan (South Sudan), White Nile, Sudd; 35 = Holotype: lateral profile viewed from slightly apicodorsal view to see the aperture rim. 36-38 = Paratypes: Sudan (South Sudan), White Nile, Sudd.

easily from the other member of the $A$. meyi species group was determined by Barnard (1980) as $A$. dispar, the nominate species of another species group, the $A$. dispar species group. This new species, like the other know 3 species of the A. meyi species group (A. felalla, A. karima, A. meyi) has the aperture rim moved dorsad as compared to the apical rim position at the $A$. dispar species group. Athaloptera pricei sp. nov. differs from the known species of the group by having the lateral profile of the phallic head abbreviated, more rounded, not elongated; the lateral profile is more produced ventrad into variously developed ventral triangle hump. 
Description. Medium-sized species. In alcohol the head and thorax yellowish brown, legs yellow, abdomen light, darker dorsally. Spur formula 032. Forewing length around $12 \mathrm{~mm}$; wing colour pale, fading to yellowish brown; less pronounced and variously discernible seven brown spots present on cross-veins and on fork junctions. Sc and R1 sinuous apically, fork 4 is short stalked in forewing. Fork R4 in hindwing sessile. The basic structure of the male genitalia is similar to $A$. karima, but differs by the divergences in the phallic head formation as discussed in diagnosis.

Etymology. This species was named and dedicated to Benjamin Price, from the Natural History Museum, London to remember his significant contribution by sending historic and newly collected materials to the revisions of several limnephilid genera.

\section{REFERENCES}

BRAUER, F. (1875): Beschreibung neuer und ungenügend bekannter Phryganiden und Oestriden. Verhandlungen der Zoologisch-Botanischen Gesellschaft in Wien, 25: 69-78.

KIMMINS, D.E. (1962): New African Caddis-flies (Order Trichoptera). Bulletin of the British Museum (Natural History) Entomology, 12(2): 81-121. doi: $\underline{\text { 10.5962/bhl.part.5873 }}$

Lestage, J.-A. (1936): Notes trichoptérologiques. XIV. Les composantes de la faune sud-africaine et la dispersion transafricaine de quelques espéces. Bulletin et Annales de la Societe Royale Belge d'Entomologie, 76: 165-192.

Marlier, G. (1943): Trichopteres du Congo Belge. $R$ evue de Zoologie et de Botanique africaines, 37: 64-88.

Oláh, J., Andersen, T., Chvojka, P., Coppa, G., Graf, W., Ibrahimi, H., Lodovici, O., Previsic, A. \& VAlle, M. (2013): The Potamophylax nigricornis group (Trichoptera, Limnephilidae): resolution of phylogenetic species by fine structure analysis. Opuscula Zoologica, Budapest, 44(2): 167-200.

OlÁH, J., ChVoJKa, P., Coppa, G., Graf, W., IBraHIMI, H., Lodovici, O., Ruiz Garcia, A., SÁInZBARIÁIN, M., VALLE, M. \& ZAMORA-MuÑOZ, C. (2014): The genus Allogamus Schmid, 1955 (Trichoptera, Limnephilidae): revised by sexual se- lection-driven adaptive, non-neutral traits of the phallic organ. Opuscula Zoologica, Budapest, 45(1): 33-82.

OlÁH, J., ChVojKa, P., COPPA, G., GOdUnKo, R.J., LOdOVICI, O., MAJECKA, K., MAJECKI, J., Szkczesny, B., URBANIC, G. \& VAlLE, M. (2015): Limnephilid taxa revised by speciation traits: Rhadicoleptus, Isogamus, Melampophylax genera, Chaetopteryx rugulosa, Psilopteryx psorosa species groups, Drusu bolivari, Annitella kosciuszkii species complexes (Trichoptera, Limnephilidae). Opuscula Zoologica, Budapest, 46(1): 3-117. doi: 10.18348/opzool.2015.1.3

Oláh, J., Chvojka, P., Ciubuc, C., Coppa, G. \& IBRAHIMI, H. (2016): New incipient species under reinforcement in the Drusus discolor new species complex (Limnephilidae, Trichoptera). Folia Historico Naturalia Musei Matraensis, 39: 105130.

Oláh, J., BeshKov, S., ChvojKa, P., Ciubuc, C., COPPA, G., IBRAHIMi, H., KovÁCs, T., MEY, W. \& OLÁH J. JR. (2017): Revision of Drusinae subfamily (Trichoptera, Limnephilidae): divergence by paraproct and paramere, speciation in isolation by integration. Opuscula Zoologica, Budapest, 48(Suppl. 1): 3-228. doi: 10.18348/opzool.2017.S1.3

OlÁH, J. \& OLÁH, J.JR. (2017): Fine phenomics applied to the Nectopsyche genus (Trichoptera): species delineation by speciation traits. Opuscula Zoologica, Budapest, 48(2): 117-184. doi: 10.18348/opzool.2017.2.117

OLÁH, J. (2018): Species delineation and description in Aethaloptera Brauer genus by phallic head (Trichoptera, Hydropsychidae, Macronematinae). Opuscula Zoologica, Budapest, 49(1): 3-16. doi: 10.18348/opzool.2018.1.3

StATZNER, B. \& GiBON, F.-M. (1984): Keys to adult and immature Macronematinae (Insecta: Trcihoptera) from the Ivory Coast (West Africa) with notes on their taxonomy and distribution. Revue d'Hydrobiologie Tropicale, 17(2): 129-151.

UlMER, G. (1951): Köcherfliegen (Trichopteren) von den Sunda-Inseln (Teil I). Archiv für Hydrobiologie, 19(Suppl.): 1-528.

WEIDNER, H. (1964): Die entomologischen Sammlungen des Zoologischen Staatsinstituts und Zoologischen Museums Hamburg. Mitteilungen aus dem Hamburgischen Zoologischen Museum und Istitut, 62: 55-100. 